\title{
An exploratory study on the conditions of health, safety and environmental affairs of very small and small-size enterprises in Brazil
}

\author{
Carlos André Vaz Junior ${ }^{\mathrm{a},}$, , Roberto de Araujo Mendonça ${ }^{\mathrm{b}}$ and Cláudia do Rosário Vaz Morgado ${ }^{\mathrm{b}}$ \\ ${ }^{\mathrm{a}}$ Departamento de Engenharia Química, Escola de Química, UFRJ, Sala E-209, Bloco E, Centro de Tecnologia, \\ Ilha do Fundão, Rio de Janeiro, Brasil \\ ${ }^{\mathrm{b}}$ Gestore, Escola Politécnica,UFRJ, Sala I-122, Bloco I, Centro de Tecnologia, Ilha do Fundão, Rio de Janeiro, \\ Brasil
}

\begin{abstract}
This paper focuses on the reality of very small and small enterprises (VSSEs) in Brazil, concerning health and safety management of their workers. These companies tend to operate in a few administrative levels. The owners' health and safety culture is fundamental for the implementation of preventive measures. The VSSEs end up adopting merely reactive and underthe-law actions. In order to understand such reality, a questionnaire was elaborated especially for the reasearch made. Fiftyfive very small and small enterprises of the industrial, commercial and service sectors were selected. The research confirmed the reactive attitude shown by the VSSEs, thus demonstrating that none of the companies involved presented policies of safety and health. Even though not holding policies, programs or scopes of their activities, $22 \%$ of them revealed to have a clear definition of the responsibilities of their high level administration. Nevertheless, $10 \%$ had financial resources allocated to this sector. Such companies do not count on a frequent safety and health support. The ignorance on it leads them to take a reactive action. This study reaches its objective on contributing to the debate, besides indicating that the way to improvement is on the strict cooperation between governments, companies, workers and society.
\end{abstract}

Keywords: Very Small and Small Enterprises, Safety Management and Health, Health and Safety Culture

\section{Introduction}

On the last decade, the accelerated industrialization, sustained by the scientific knowledge transformation into technology and by the revolutionary Information Technology, determined drastic changes in the working world. These changes transformed the organizations drastically as well, bringing to their agendas subjects such as environment, health, cultural diversity, human rights, ethics and social responsibilities, not only as a competitive differencial, but as a survival condition [2]. Therefore, it is more and more difficult to speak about a working environment as if there was a world inside and another outside of the factories.

For the organizational management, the industrial development and the technological advance that took place in the last half of the XX Century, established new parameters of competetivity and brought out social-environmental challenges originated in the enterpreneurial activities. According to Demajorovic [5], the industrialization expansion, which began threatening flora and fauna, risks now the human being. If one stays just in the health and safety areas, according to the IWO - International Work Organization, four persons die per minute in the world due to accidents at work. In Brazil, according to a re-

${ }^{*}$ Corresponding author. E-mail: cavazjunior@eq.ufrj.br 
search done by the Social Safety Ministry, 2.757 workers lost their lives during the year of 2008 and 13.614 became permanently disabled.

Therefore, facing these challenges, these organizations are looking for new forms of management, in order to secure the market, to hold talents and to produce under a social-environmental balance. Such is the case of tearing up the financial profit paradigmas as reasons of existence and to advance towards a new reason of being for the enterprises in which the profit is seen as a result of the balance between economical, social and environmental factors.

According to Kusyk and Lozano [9], a few academic studies evaluate the ethics and the social responsibilities of small and medium enterprises, while several works focus on large corporations. Even though the social responsibility has been frequently associated to large companies, the influence of the small ones, if considered as a group, is enormous. In general, the very small and small companies feel obligated to answer to demands on safety, health and environmental working areas without being prepared for it as well as needing but not counting on support for it. One must remember that a small company is not a smaller version of a large enterprise. In fact, it is another organization. We may compare it by saying that a child is not an adult under a smaller stature, they are not similar (Andrade, 2008).

Safety, health and environmental integrated management practices at work are generally related today to the image of large corporations that invest a great deal of money on environmental projects, exhibit international certificates, consolidate an image of an environmentally correct company and, last but not least, communicate their results through reports and social balances. Nevertheless, although large enterpreneurial organizations represent a great deal of the IGP (Internal Gross Product), they represent only 1\% of the total of the enterprising of our country. The VSSE respond for $99 \%$ of the total number of formal companies, according to Figure 1 [8]. Simultaneously, very small and small enterprises have a large participation on the number of jobs generated in the country. In 2009 , these numbers represented $40 \%$ of employment in Brazil [8].

While large enterpreneurial organizations have the necessary resources to change and improve the working environments, the VSSEs lack both resources and information. But the VSSEs are the real great generators of jobs, and are the ones to show a high geografic distribution and community integration capacity, characteristics that can enlarge the impact of its social-environmental activities.

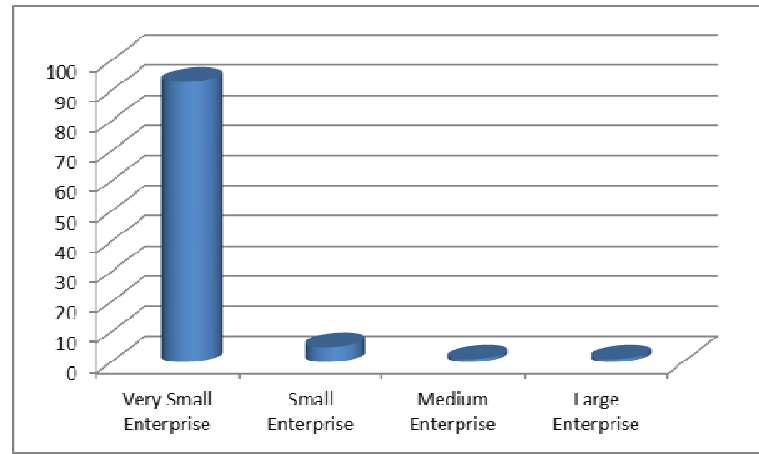

Figure 1: Percentage of the number of companies by size in Brazil.

\section{Very small and small enterprises}

In the whole world and specificially in Brazil, the very small and small enterprises (VSSEs) are an important instrument of economical and social inclusion. The sector has a highlighted participation in the access to job oportunities and in the economical development of the country.

\subsection{Classification}

There are several parameters to define and classify the companies in very small and small - it does not matter if for a simple study or for legal situations. A parameter used constantly for the classification is the amount of workers in these companies. Therefore, it is considered a very small company the organization that employs up to nine persons in commerce and service activities and up to nineteen persons in the industrial sector. The small company employs from ten to forty-nine persons in commerce and service activities and from twenty to ninity-nine persons in the industrial sector.

Similar classifying methologies are used in several countries. The European Community has its definition for very small and small enterprises based on the recommendation 90/280/EC of 2003, which defines a very small enterprise holding less than 10 employees, the small company holding from 10 to up to $49 \mathrm{em}$ ployees, the medium company holding from 50 to up to 249 employees and the large enterprise holding over 250 employees.

\subsection{Life cycle}

In Brazil, the majority of the very small enterprises close their activities shortly after one year of its busi- 
ness and social activities, according to researches made on this subject.

Among the main factors that contribute for the premature closing of their activities are those related to the lack of technology and better prepared labor, low flexibility and agility on the decision making, difficulties on the obtaining of financing lines, etc...

\section{Accidents at work}

Linked to economical, structural and market orders difficulties, the data from the Social Safety Ministry reveal a huge incidence of accidents and illnesses related to working conditions in the very small and small enterprises. According to the Social Safety Ministry, this number goes up to four times the number of similar problems found in large enterprises, showing, therefore, by an unmistakable form, the urgent need that the VSSEs find their way.

International statistics show how falible the preventive safety practices are in the very small and small enterprises environment - and not only in Brazil. According to A. Gomes [1], in the European Community, the very small and small enterprises are responsible for more than $82 \%$ of all occupational injures, going up to $90 \%$ of the fatal accidents. The number of workers injured in small companies is much larger than the acceptable limits [6]. The IWO points out that $41 \%$ of the severe accidents occur in companies holding less than 25 employees.

The diversity of the acting areas and ways of administration in small enterprises make any generalization on this field very difficult. In the majority of the cases, safety problems in small companies are much more related to the bad management than to the real magnitude of the danger present in the work performed. The capacity of the company owner to recognize risks is limited, and as a consequence, the acceptance of the need to adopt more efficient safety policies is limited as well.

Studies developed by Schmid et al [7] demonstrate the need to give more attention to small and medium companies at the United Kingdom, in particular. In the last years the implementation of new rules and regulations by the government showed as a result, and according to the authors [7], an increase of the costs for the companies. Due to the nature of these costs, proportionally these costs may go up significantly to six times more in small and medium companies than in larger companies. This happens because the smaller companies are less structured, not having departments dedicated exclusively to follow legal demands. Although it is not possible to assure that there is a co-relation between them, the number of bankruptsies of small and medium enterprises in the UK, grew $14 \%$ in the last 20 yeras, following the regulation process.

\section{The leader's role}

In order to implement a health and safety management system, first of all it is necessary to count on the effective commitement of the company's top administration. It is the role of the board of directors to elaborate clever and clear policies, priorizing the actions, thus defining goals and indicators that may allow the monitoring of such implemented actions.

In the very small and small enterprises, the head of the company usually is the owner of the company. Nevertheless, this administrator rarelly believes in the prioritization of safety as an integral and very important part of the business.

Hoivik, Moen and Haukelidk [3], in their study of health and safety cultures, highlighted: "What do the employees expect from the manager? As a matter of fact, they want a manager that communicates with them and shows interest on subjects related to health and safety besides motivating them. The manager must also understand the existing challenges of the working environment. The manager must, through his own practices, show good habits. He must be clear and coherent not only with his instructions but also trhough his own example".

\section{Resarch Methodology}

For Marconi and Lakatos [4]: “(..) all research implicates in data raising of the place itself where the phenomena occur. These data can be achieved by two forms: through a field research and lab research".

In this paper we use a field research taken through a questionnaire application, focusing on the understanding of the reality of the VSSEs. The direct interview with the involved actors is a good method for studying a concept, subjective experiences and to understand them. This type of study allows the researcher to understand the world according to the point of view of the interviewed people, standing free from prejudices and previously conceived ideas [3].

Fifty-five companies were selected from a database bank of more than 800 Brazilian VSSE. A sample of the "industry", "commerce" and "services" segments was selected. Although each one of the segments presents its own characteristics and de- 
mands specific treatment, for this exploratory study such particularities were not taked into account.

From the fifty-five enterprises originally contacted, forty-six agreed to participate on the research.

The form applied (Figure 2) consisted of items divided in three thematic groups (profile of the interviewed person and company, responsibility of the Safety Environmental and Health Management). The same was applied personally in each one of the companies, being answered by a representative (owners or managers) indicated by them.

The collected information was then analyzed on a systematic way. With the objective of facilitating the understanding of the results, most information was organized as graphics, thus allowing an easier and a more pointed analysis.

In order to guarantee the privacy of the participating companies, the answers were never linked to any company involved in the study.

\section{Results}

The following results presented help the understanding of the reality of the VSSEs, in the face of the need to develop and adopt preventive positions in the safety, environment and health contexts.

\subsection{Researched companies profiles}

From the forty-six companies researched, which answered the questionnaire, $50 \%$ are very small enterprises and the other $50 \%$ are small. Among the very small companies, 7 are from the industrial sector, 6 come from the commerce sector and 10 belong to the services area. Among the small companies, 5 are from the industrial branch, 9 come from the commerce sector and 9 act in the services sector.

\subsection{The interviewed profiles}

Concerning the profile of the representatives interviewed, $83 \%$ act in the administration sector, while $17 \%$ act in the production area. The predominance of the company representatives that answered the questionnaire belonging to the administrative area, confirms the hypothesis that the VSSEs hold hierarchic chains for a short period of time. This way, the so called "high management" is usually restricted to the owner of the business, who has the responsibility to administer the company, taking care of the administrative, financial, personnel, fiscal and other areas, therefore having almost no time left to dedicate to accident prevention.

Other interesting data obtained from the results is that in relation to the gender of the interviewed leaderships, $60 \%$ are females. This confirms today's tendency of women assuming high positions in the management of companies.

\subsection{Responsibility in the management of the Health, Safety, and Environment (HSE)}

The research points out that very small and small enterprises do not have sufficient knowledge of the benefits and characteristics of safety, environmental and health management

Question \#1 tries to measure the application of safety and health policies in the VSSEs. Among the companies which participated on this research, $87 \%$ revealed to not make use of this basic tool for the development of a preventive safety program. A significant number of representatives of the companies, about $13 \%$, did not know what to answer. In not knowing how to answer to these questions, these professionals show a picture even more drastic than the one exhibited by those whose companies do not use such policy. The employee simply does not know the significance and importance of this subject. Not one enterprise revealed to have safety and health policies (Figure 3).

During the enterviews, it was possible to observe that the same way many interviewed representatives did not know whether the company had policies or not on safety and health, there was also a strong ignorance on the technical and legal aspects related to the subject.

Facing the previous answer, the following question concerning the publishing and promotion of the policies at all levels of the organization, showed the same tendency.

Concerning the existence of goals and objectives of safety and health aligned with their policies (Question 3), only one company answered "yes" (Figure 4). The representative explained that this "Rio de Janeiro" enterprise was an afiliated of a medium size company located in another State of Brazil. This way, the afiliated already shows a few traces of preventive actions. Nevetheless, the representative does not classify such actions as "safety policy" at Question 1. 
FIELD RESEARCH OUESTIONNAIRE

FIELD RESEARCH QUESTIONNAIRE
RESEARCH FOR EVALUATION OF THE ENVOLVEMENT OF THE VERY SMALL AND SMALL ENTERPRISES IN A HSEs MANAGEMENT
SYSTEM

PROFILE OF THE INTERVIEWED:

SECTOR : ( ) ADMINISTRATION ( ) PRODUCTION

GENDER: ( ) MALE ( ) FEMALE

EDUCATION ( )MEDIUM ( )TECHNICAL ( ) ACADEMIC

PROFILE OF THE COMPANY:

SECTOR: ( )INDUSTRY ( ) COMMERCE ( ) SERVICES

NUMBER OF EMPLOYEES:

IS CONSIDERED AS: ( ) VERY SMALL COMPANY

( ) SMALL COMPANY

RISKS DEGREE: ( ) 1 ( ) 2 ( ) 3 ( ) 4

RESPONSIBILITY OF THE HSE MANAGEMENT

SAFETY AND HEALTH POLICIES

1- Safety and health policies?

( ) yes ( ) no ( ) didn't answer

2- Publishes and promotes policies of safety and health at all levels of the Organization?

( ) yes ( ) no ( ) didn't answer

GOALS AND OBJECTIVES

3- Focuses on goals and objectives of safety and health, aligned with its policies measureable through reactive and proactive indicators? ( ) yes ( ) no ( ) didn't answer

\section{HSE MANAGEMENT PROGRAMS}

4- Management programs addressing safety and health goals and objectives? ( ) yes ( ) no ( ) didn't answer

ORGANIZATIONAL STRUCTURE AND RESPONSIBILITY DEFINITIONS

5- Functional organogram with safety and health attributions?

( ) yes ( ) no ( ) didn't answer

6- Clear definition of attributions and responsibilities of top management?

( ) yes ( ) no ( ) didn't answer

7- Documentation of responsibilities, authorities and description of positions, including safety and health? ( ) yes ( ) no ( ) didn’t answer

8- Resources for safety and health previously budgeted in the costs structure?

( ) yes ( ) no ( ) didn't answer

\section{TRAINING IN HSES}

9- Training program for the workers in the safety aspect? ( ) yes ( ) no ( ) didn't answer

10- Training program for the workers in the health aspect?

( ) yes ( ) no ( ) didn't answer

INVOLVEMENT AND COMMUNICATION

11- Mechanism used for involvement and communication in safety and health for the team of workers? ( ) notice board ( ) internal report ( ) others

DOCUMENTATION

12- Mechanism used for structuring and organizing the documentation of the HSE systems?

Answer:

DATA AND DOCUMENTS CONTROL

13- Mechanism used to register, update, store and recover the information on health and safety? Answer:

RULES AND PROCEDURES FOR OPERATIONAL CONTROL

14- Own Rules and operational procedures on safety and health? Answer:

OTHERS:

15- Housekeeping and organization program? ( ) yes) ( ) no ( ) didn't answer

16- Mechanism for evaluating products and equipments/devices to be acquired following safety rules?

( ) yes ( ) no ( ) didn’t answer 


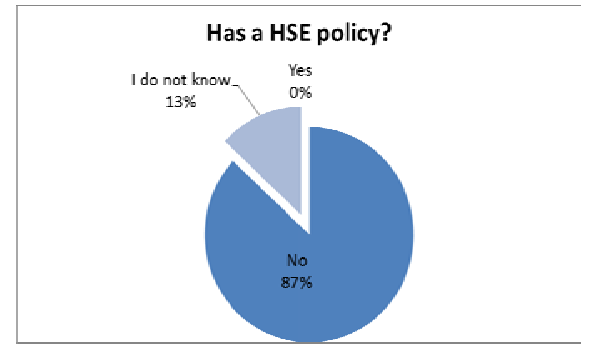

Figure 3: Do you have safety and health policies?

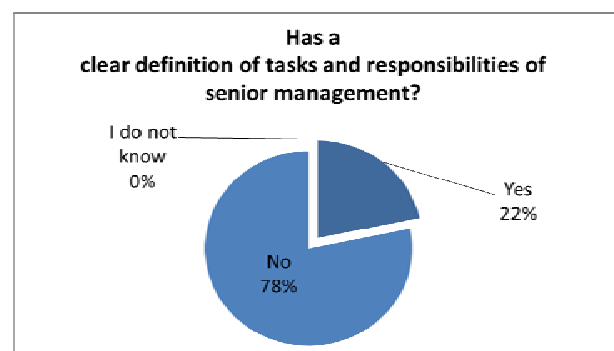

Figure 4: Do you have goals and objectives on safety and health, aligned to its policies, measureable through reactive and proactive indicators?

The existence of management programs focusing on goals and onbejctives already mentioned in the previous question, is evaluated by Question 4. According to expectations, the achieved result repeats the previous frame with an absolut majority of $91 \%$, answering that they do not hold management programs in this area. The company that said to have goals and objectives for safety and health, is therefore, the only company to have management programs projected to achieve them.

Question 5 asks whether the company has in its board professionals with specific attributions on safety and health targets. All the companies involved were unanimous in answering that they did not. Brazil does not require legal attributions from these small companies concerning the contracting of such professionals.

Nevertheless, when questioned if the high administration held clear definitions of the attributions and responsibilities, the results surprised. A percentage of $22 \%$ of the companies responding to the questionnaire said to have well defined attributions (Figure 5). This means that although without policies, goals and such objectives, a significant part of the studied companies presents definition of the attributions and responsibilities of the high administration. A similar result was obtained concerning the existence of documents that define responsibilities and description of positions (Question 7). On the other hand, a little more than $10 \%$ of the enterprises has a financial resource budgeted for the safety area (Question 8).

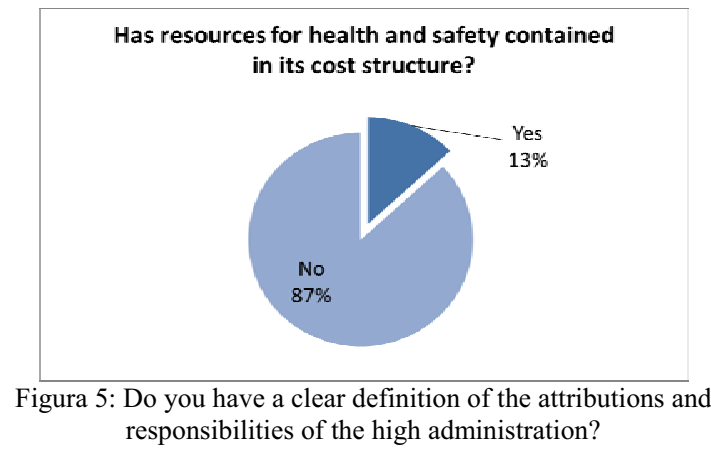

Questions 9 and 10 address the training in health and safety. By separating this subject in two questions we had the objective of checking eventual differences on the way of looking for safety and health. Nevertheless, the results were identical for both questions. Among the analyzed companies, 17\% developed training programs for these sectors. It is possible to observe that mainly the companies that act on sectors of health and food exhibit a major concern in better training their employees on these subjects. This happens due to a closer presence of fiscal organisms, such as ANVISA (National Agency of Sanitary Vigilance).

Besides the training itself, other practice adopted by the companies is the publishing of subjects related to prevention on safety and health. As we can see on Figure 6, the tool mostly used by the VSSEs for publishing and communication of notices related to safety and health on work is the notice board. From the forty-six companies that participated on the research, forty of them employ this method. Other used procedure is the internal report.

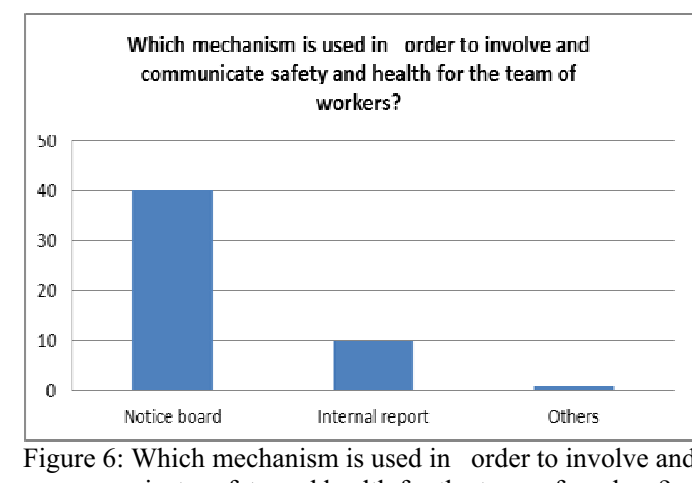

communicate safety and health for the team of workers?

Referring to the documentation related to health and safety systems, Question 12 asked which me- 
chanism was being used for structuring and organizing such documentation. An unanimous answer rose back, indicating the PPRA (Environmental Risks Preventive Program) and the PCMSO (Medical Control Program of Occupational Health). It was noticeable during the interviewes that a great part of the companies do not understand the real sense of preventing programs, responding to it exclusively when there is a legal measure that must be followed.

The PPRA and PCMSO are also indicated as registration, storage and information recovery mechanisms, as evidenced in Question 13.

Only four companies informed to have developed and used their own rules and procedures concerning health and safety (Question 14). The four companies to answer so, do have in commom the fact that they work in fields of much higher risks. One of them informed that it was obligated to create procedures due to the need to work in association with other companies in the market place.

In Question 15 one can verify a preocupation on aspects of the work organization, such as coordination and housekeeping. Only two companies (5\%) said to have programs related to these aspects. Equal number simply ignores or does not know how to answer to the subject.

Finally, at Question 16, other important practice for the development of actions projected in the field of prevention arises: "Does the company have a mechanism capable of evaluating if products and equipments/devices to be acquired answer to safety rules?" All the companies interviewed responded to not have this concern. Which means, although confirming to adopt rules and procedures on health and safety, as well as training programs, none of the companies involved evaluates products and equipments/devices acquired concerning safety rules.

\section{Conclusion}

If on one hand the study of the reality of very small and small enterprises in Brazil confirms that these are fundamental for the progress of the country, on the other hand it shows, as well, that the majority of the VSSEs clearly perpetrates a reactive conduct. The enterprises are stimulated by fines originated from the fiscalization or if and when accidents happen. In its majority, they do not count consistently on support for their safety, health and environment.

Such companies believe that being small, they should be dispensed from the accomplishment of several safety rules. They do not see that the risks are not smaller on the proportion of the number of employees.

When alleging reasons for the lack of an integrated system of safety, health and environment, which is certainly costly, the directors do not understand that prevention is an investment, not an expense!

This way, this study reaches its objective by contributing to the debate with a critical look of the VSSEs' difficulties, besides pointing out that the best way to have better companies is focusing on and contemplating a strict cooperation with governors, employers, workers, class associations and the civil society organized as a whole.

\section{References}

[1] A. Gomes, Ações de saúde e segurança no trabalho na micro e pequena empresa: proposta de um instrumento de autoavaliação. Ph.D. Dissertation, Centro Universitário SENAC, 2005.

[2] D. Grayson and A. Hodges, Compromisso social e gestão empresarial, in:Publifolha, São Paulo, 2002.

[3] D. Hoivik, B. Moen, E. Haukelidk. An explorative study of health, safety an environment culture in a Norwegian petroleum company. Safety Sci. Vol 4, No 7, 2009.

[4] E. M. Lakatos, M.A. Marconi, Metodologia do trabalho científico: procedimentos básicos, pesquisa bibliográfica, projeto e relatório, publicações e trabalhos científicos. Atlas, São Paulo, 1992.

[5] J. Demajorovic, Sociedade de risco e responsabilidade socioambiental: perspectivas para educação corporativa, in: SENAC, São Paulo, 2003.

[6] K. Jorgensen, N.J. Doijim, H. Troen, Accident prevention in SME using ORM, Journal of Safety Science, Vol. 48, 2010, pp.1036-1043.

[7] R.A. Schmid, D. Bennison, S. Bainbridge, A. Hallsworth, Legislation and SMS retailers - compliance costs and consequences, International Journal of Retail \& Distribution Management, Vol. 35, No 4, 2007, pp. 256-270.

[8] SEBRAE/RJ - Serviço de Apoio a Micro e Pequena Empresa, Detalhes definindo sua empresa - Definir seu empreendimento, alguns dados sobre micro e pequenas empresas e empreendedorismo (2009).

[9] S.M. Kusyk, J.M. Lozano, Corporate Responsability in Small and Medium-sized Enterprises SMS Social Performance: a Four-cell Typology of Key Drivers and Barriers on Social Issues and Their Implications for Stackholder Theory, The International Journal of Business in Society, Vol. 7, No 4, 2007. 